IMMUNOLOGICAL ASPECTS OF NEOPLASIA - THE ROLE OF THE THYMUS 


\section{Cancer Growth and Progression}

Volume 17

Series Editor:

Hans E. Kaiser, D.Sc.

Professor,

Department of Pathology,

School of Medicine, University of Maryland, Baltimore, MD, U.S.A.

\& Department of Clinical Pathology, University of Vienna, Austria

Associate Editor:

Aejaz Nasir, M.D., M.Phil.

Department of Interdisciplinary Oncology-Pathology,

H. Lee Moffit Cancer Centre \& Research Institute,

University of South Florida, Tampa, FL, U.S.A.

Production Assistant:

Yasmin Qayumi, B.S. 


\section{Immunological Aspects of \\ Neoplasia - The Role of the Thymus}

by

Bela Bodey, M.D., D.Sc.

Professor

Department of Pathology and Laboratory Medicine,

Keck School of Medicine, University of Southern California, Los Angeles,

\& Childrens Center for Cancer and Blood Diseases,

Childrens Hospital Los Angeles, Los Angeles, CA, U.S.A.

Stuart E. Siegel, M.D.

Professor

Department of Pediatrics,

Keck School of Medicine, University of Southern California, Los Angeles,

\& Childrens Center for Cancer and Blood Diseases,

Childrens Hospital Los Angeles, Los Angeles, CA, U.S.A.

and

Hans E. Kaiser, D.Sc.

Professor

Department of Pathology,

School of Medicine, University of Maryland, Baltimore, MD, US.A.

\& Department of Clinical Pathology, University of Vienna, Vienna, Austria

KLUWER ACADEMIC PUBLISHERS

NEW YORK, BOSTON, DORDRECHT, LONDON, MOSCOW 
eBook ISBN: $\quad$ 1-4020-2185-2

Print ISBN: $\quad$ 1-4020-2184-4

○2004 Springer Science + Business Media, Inc.

Print @2004 Kluwer Academic Publishers

Dordrecht

All rights reserved

No part of this eBook may be reproduced or transmitted in any form or by any means, electronic, mechanical, recording, or otherwise, without written consent from the Publisher

Created in the United States of America

Visit Springer's eBookstore at:

http://www.ebooks.kluweronline.com and the Springer Global Website Online at:

http://www.springeronline.com 


\section{Contents}

Series Preface $\quad$ vii

$\begin{array}{ll}\text { Contributors } & \text { ix }\end{array}$

Acknowledgements $\quad$ xi

SECTION 1 - OVERVIEW OF MAMMALIAN THYMIC DEVELOPMENT 1

Introduction 3

1. Embryology of the Mammalian Thymus 5

SECTION 2 - HISTOGENESIS OF THE MAMMALIAN THYMUS 15

2. The Reticulo-Epithelial Cellular Network of the Mammalian Thymus 17

3. Neuroendocrine Influence on Thymic Hematopoiesis Via the ReticuloEpithelial (RE) Cellular Network

4. Development of Lymphopoiesis as a Function of the Thymic 
5. The Hassall's bodies 93

6. Thymic Accessory Cells, including Dendritic-Type Antigen Presenting Cells, Within the Mammalian Thymic Microenvironment

7. Involution of the Mammalian Thymus and its Role in the Overall Aging Process

SECTION 3 - THE THYMUS AND ITS SIGNIFICANCE IN ANTINEOPLASTIC THERAPY

8. Thymic Hormones in Cancer Diagnosis and Treatment

9. Spontaneous Regression of Neoplasms: New Possibilities for Immunotherapy 


\section{SERIES PREFACE}

The present multi-volume Book Series, CANCER GROWTH AND PROGRESSION, encompasses the widest possible framework of cutting edge research in the field of neoplastic pathology and other integrated fields. Normal and pathologic growth is one of the most intensively studied yet challenging areas in pathology. Thus the individual volumes in this series focus on the topics of highest scientific interest for basic and clinical researchers, pathologists, medical and surgical oncologists and allied multidisciplinary teams interested in the study of these aspects of neoplastic growth, progression and inhibition. The range of topics covered is extensive, including but not limited to autonomous growth characteristics of malignancy, phenomena of progression of malignant growth involving the various body systems, and recent advances being made in successful neoplastic inhibition and control.

Cell function may be described as producing progression or regression, often found as alternating features in tumors or as variations between normal tissues and tumors. The source of regression in normal melanin producing cells may not be the same as in melanomas. These functions of living matter persist in all phyla of eumetazoans vascular plants as well as in particular species of fungi. However, homo sapiens are the eumetazoan species, which interest us the most.

Normal growth processes cannot be entirely understood in all its diversity until we have a thorough knowledge of what constitutes normal growth in various organisms. Complex cellular metabolic pathways are the fundamental elements of growth processes with wide variation in different tissues and organs subjected to a host of carcinogenic influences. The etiology of neoplasms that includes inherent/acquired gene defects, chemical and physical carcinogens, radioactive emissions, viruses, bacteria and parasites are too numerous to catalogue. Therefore, it would be a challenging task to address every aspect of the diverse processes of neoplastic growth and progression. In order to accomplish this goal in the most practical manner, I have invited a highly select team of distinguished authors who are among the most knowledgeable authorities in their fields, to share their expertise in various areas of normal and neoplastic growth, progression, inhibition and control. 
A specific purpose of this Book Series is to provide a broad yet comprehensive review of the topics covered that will enrich the reader with the latest and most authentic information at the cutting edge of the field from the world authorities that will be of practical utility to a wide range of professionals in the field of cancer. I have dedicated all my life to the study, teaching and research in cancer. It is my utmost desire to wish you all a great success in your fight against cancer. I hope the second edition of this series will serve as a landmark in our continued efforts to unravel the complexities of the neoplastic phenomena at the one end and to improve the quality of life and minimize the suffering of the patients with cancer on the other!

Hans E. Kaiser. D.Sc.

Series Editor 


\section{Contributors}

Professor Bela Bodey, M.D., D.Sc.

Department of Pathology and Laboratory Medicine, Keck School of Medicine, University of Southern California, Los Angeles, \& Childrens Center for Cancer and Blood Diseases, Childrens Hospital Los Angeles, Los Angeles, CA, USA

Professor Stuart E. Siegel, M.D.

Department of Pediatrics, Keck School of Medicine, University of Southern California, Los Angeles, \& Childrens Center for Cancer and Blood Diseases, Childrens Hospital Los Angeles, Los Angeles, CA, USA.

Professor Hans E. Kaiser, D.Sc.

Department of Pathology, School of Medicine, University of Maryland, Baltimore, MD, USA \& Department of Clinical Pathology, University of Vienna, Vienna, Austria. 


\section{Acknowledgements}

We dedicate this monograph in loving memory of Dr. Bodey's beloved Mother, Rossitza Derebeeva. 